\title{
The Application of Nonverbal Symbols in Intercultural Business Communication
}

\author{
Li Xiangmin \\ Beijing International Studies University \\ BISU \\ Beijing, China \\ lixm@bisu.edu.cn
}

\author{
Zhao Xin \\ Beijing International Studies University \\ BISU \\ Beijing, China \\ 1179367237@qq.com
}

\begin{abstract}
According to the linguistic theory, here we study the application of nonverbal symbols in business communication. With the rapid development of international business activities, it has witnessed the increasing importance of the study in this field. Based on the former research, this paper presents the different functions and applications of nonverbal symbols by the method of literature summary, comparative analysis, exemplification and induction. Our results suggest a widespread role for nonverbal symbols in intercultural business communication. In this study, we describe a linguistic model of the classification of these symbols in different culture and social background. In different situations, we should apply different symbols to people from different culture accordingly.
\end{abstract}

Keywords—nonverbal symbols; function; application; business communication; cultural differences

\section{INTRODUCTION}

At the end of the 1950s, J. L. Austin, a British philosopher, put forward the speech act theory for the first time, and classified the speech act into three sections: locutionary act, illocutionary act and perlocutionary act [He Zhaoxiong, Mei Deming, 1999]. And the speaker's real intention is reflected in the illocutionary act, which lays the theoretical foundation of the nonverbal communication theory.

In our daily communication, there are two main different ways to communicate with others: verbal communication and nonverbal communication. "Of course, language is the most important tool in the communicative activities of human beings, but it's not the only communication tool for us. Besides, we also rely on many other nonverbal communication symbols... In fact, verbal language often mixed up with nonverbal language in people's social communication" [Chen Yuan, 1983].

Based on the linguistic theory of former researchers, this paper systematically analyzes the different functions and various applications of nonverbal communication. Because different country has different culture, historical background, and social customs, all these factors will bring different barriers for businessman from different cultural background to communicate. Therefore, this paper aims to analyze these different applications in specific occasions and find some general rules during international business communication, so as to promote the internationalization of business activities.

\section{THE MAJOR FUNCTION OF NONVERBAL COMMUNICATION}

Merabin Albert, a psychologist, has proposed a formula: the total information of conveying a message $=7 \%$ (words) $+38 \%$ (language) $+55 \%$ (facial expression). In the expression of feelings and attitudes, language only accounts for $7 \%$ of the communicative behavior, and the information conveyed by the tone and facial expression accounts for 93\%[Li Mengya, Zhao Fang, 2009].

Samovar (2003) said: "In face to face communication, the information conveyed through verbal language is only account for $35 \%$, and the other is conveyed through nonverbal symbols."

Therefore, nonverbal communication is very necessary and effective in the whole process of business communication. Generally speaking, there are five functions for nonverbal communication:

\section{A. Substituting Function}

Its main purpose is to substitute the information that unable or inconvenient to express, for example, for the people unable to communicate by verbal language, they can use body language to express their feelings and communicate with others And sometimes, limited by time, place or other conditions, only by nonverbal symbols can one express the information freely.

In business negotiation, sometimes one is unable to express the whole information through verbal communication. Then nonverbal symbols can replace verbal symbols to complete the communication, and it even can complete the communication task alone. For example, in an Indian tribe, where no one can speak a language, people there mainly express feelings and ideas through gestures.

In the basic skills of nonverbal communication, head language is the most used one in our daily life, including nod language and shake language. Just for the nod language, some experts have summarized 11 different meanings as below: compliment, agree, admit, thanks, favor, assent, satisfaction, recognize, understand and comply. [Kuang Xinhua, Ceng Jianping, 2004]. Under different context, we should try to fathom the real intention of speaker by his facial expression and body language. 


\section{B. Supplementing Function}

It mainly aims to supplement the information that cannot fully convey. There may be some information deficiency in verbal communication, especially in the cross cultural business communication. Nonverbal communication can make up this deficiency.

American scholar Ferrera Davis summarized: "When you realize that even when such words 'I hate you' also make you feel her affection, then the importance of tone and facial expression is obvious."

In 1960, Kennedy and Nixon held a campaign speech for the presidential election. Despite Kennedy was younger than Nixon and lack of political experience at that time, but he was good at mastering both his verbal and nonverbal language in the tour speech, such as facial expression, gestures, mental state and so on. Through nonverbal communication, Kennedy skillfully showed his personal charm and public leadership in political affairs. As a result, he won the support of a majority of voters by this in the presidential election. Through the example above, of course, we cannot owe Kennedy's success to his use of non-verbal communication entirely; however, there is no doubt that the use of these skills is a part of his success. Without these skills, his much political talent won't have place to play.

\section{Negating Function}

It means to negate the information expressed in verbal language by speaker. These information usually do not comply the speaker's real intention.

One may be insincere in his words through verbal communication, but he cannot conceal his real feelings in his body language. Body language is the real outpouring of one's feelings, when it conflicts with verbal language, body language is more authenticity.

Recently, the research of micro expressions and body language is rising; it's mainly to find the true intention which the speakers intend to conceal behind their micro expressions and slight body language. The theory concluded from these studies is widely used in criminal interrogation and business negotiation.

In the process of police interrogation, prisoners always try to cover their crimes, the verbal communication is usually not sufficient to dig out the facts of the crime, then the police need to apply the nonverbal communication skills to observe the micro expressions and body language of the criminals to find out the truth. In fact, many serious crimes are finished in this way. Similarly, in business negotiation, both sides try to hide their own bottom line or the lowest quotation. At this time, the success of negotiation is up to whether the negotiators have the ability to master the nonverbal communication skills to some extent.

\section{Stressing Function}

It targets to stress the main intention of speaker, to highlight these information from the other ones which unimportant, common or useless.
It mainly emphasizes the special point which contained the most valuable information in verbal communication, thus to greatly improve the effect and efficiency of auxiliary communication.

For example, when the speaker tries to emphasis his point of view on certain event, he often strengthens the information he want to convey through his eyes and gestures and so on. The typical case is the gesture of directing the way for people. When being asked the direction of some place, people always use their hand to support language to show somebody the way. In this case, the use of gesture is a kind of nonverbal communication. Meanwhile, the meaning it contained is different according to the extent of arm. For example, the more the arm was stretched out, the longer the distance is. The gesture can stress the distance.

\section{E. Regulating Function}

In order to regulate the disordered information conveyed through verbal language, one can use nonverbal symbols to put this information in order, so as to easy to understand for listeners.

In business communication, the exchange of ideas, as well as the reaction of emotion and the change of attitude, all of these activities often need the application of non-language communication to support.

For example, it may be inconvenient or impossible for someone to voice his point of view in a meeting, then he could raise his hand to show that he had something to say. Usually, a conversation is started with a handshake, which accompanied with eye contact and smile and nod; and end with a farewell handshake, which accompanied with eyes gradually out of contact.

According to these five functions of the nonverbal communication, we can see that it is an essential tool in our intercultural business communication. But the importance is how to apply it in the reality. The process may be related to many factors, the most important factor is the cultural differences between different countries.

\section{THE APPLICATION OF NONVERBAL COMMUNICATION}

In general, nonverbal communication can be classified into the following four categories: spatial language, facial language, body language and image language. Each of them has its distinctive features.

\section{A. Spatial Language}

American scholar Hall studied people's demand for space, according to his own research; he roughly classified it into four kinds:

\section{a. Intimate distance.}

It is generally defined as within 45 centimeters, it usually occurs between the close relationships, such as family members and lovers and close friends. It is the most intimate one among these four spatial languages.

b. Personal distance. 
It generally ranges from 45 centimeters to 80 centimeters, it usually applied between the friends not so close and colleague. This distance is very difficult to master. If stay too close, it could give people the sense of being invaded; otherwise if too far, a sense of distance.

\section{c. Social distance.}

Generally speaking, it is defined between 1.3 meters to 3 meters, it usually occurs between strangers and in some formal social occasions. Social distance is also widely used in business communication among different countries. It's up to the specific circumstances. If the communication goes smoothly, the distance between two parts could be narrowed to next stage, and then they can try to establish a long-term cooperative relationship.

\section{d. Public distance.}

The definition of public distance is more flexible, it usually ranges from 3 meters up to the space can be heard and saw. It mainly used in the public places, such as theater, lecture hall, square and so on.

In real life, it is usually difficult to accurate the reasonable distance by eye in business communication; on the other hand, it varies from country to country for the demand of space according to different cultures.

For example, Americans don't like to stay too close with others, so when communicate with them; the distance should be kept as the third one, that is to say, social distance. On the controversy, the people from Arab, Africa and Latin America prefer communicate in a close distance. For the two parts from totally different cultural background and social habits, it is difficult for them to sit by the same table to communicate. Therefore, it requires the two parts to understand each other's' culture to avoid unnecessary misunderstanding and keep the communication smooth.

\section{B. Expression Language}

As an old saying goes: "Eyes are the windows of the soul", so the study of expression language is also reflected in the study of eye contact. People in Britain and the United States particularly focus on the contact of eyes in conversation, it is also an important rule that when communicating with the British and American customers. When you talk with them, they will keep eyes on you all the time to show that they are interested in what you are talking about, but actually he maybe not really interested. They just want to show their respect to you.

However, people in oriental society always don't try to keep their eyes on you. They usually remove their eyes from time to time to show humility and respect for others. Too much eye contact is considered to be humble and not polite to others.

For example, Japanese managers often buries with closed eyes in the negotiations, in fact, this is a nonverbal language, that is to say, they are commit themselves to what you are talking about. But in the eyes of Western countries such as Britain and the United States, the escape of eyes is often regarded as lack of attention, dishonesty and not confident in his own performance.

\section{Body Language}

Body language is the most frequently used tool in business communication, and it has many kinds of forms. The same form of certain body language may express different meanings in different cultural backgrounds.

Typically, take the gesture "OK" for example, it is widely used in various occasions, the most common meaning of it is to express praise, agree with somebody. But if placed in a different culture background, its meaning is quite different from one to one. In France, it means "zero" or "worthless"; in Germany and Brazil, it is a very rude behavior, even with some insulting meaning; in Japan, it is on behalf of money, which just like a coin's shape. So in Japan, when one business negotiation was completed, people from foreign country maybe make the gesture "OK" to express approval or praise. Under this situation, Japanese are likely to change their attitude, because they may regard this gesture as the suggestion of asking them for money. Such communication barriers can even lead to the breakdown of negotiations during business communication.

\section{Image Language}

Image language mainly refers to person's appearance and a kind of displays of mental state, it is a silent language, it reflects a person's potential personality, identity, mental state and so on. In the process of communication, people should also pay special attention to their own image language. It is the way to show respect for others.

Generally speaking, one should be dressed in a generous, dignified and neat style. Don't be dressed in outlandish costume. Accessory should be simple and appropriate to one's style, not too vulgar, too messy or too dazzling. All in all, it should be compatible with the specific occasion and one's identity.

\section{CONCLUSION}

In the context of globalization, it is not only a flexible technique, but also a comprehensive art to apply nonverbal communication in intercultural communication. Its wide use usually makes a decisive role in business communication. Meanwhile, because of the differences in historical background, culture and regional customs, there are great differences in the application of nonverbal communication. It requires people to learn from each other, and learn to comply with the specific cultural background. Only in this way can we reach the goal of business communication.

Through this comparative study, many different function and application of nonverbal symbols have been found. It is the authors' hope that these findings will bring some inspiration to those people who undertaking intercultural communicative activities. At the same time, there are some limitations in this research, for example, the lack of cases to support the theory I used. With the rapid development of society, some new theories of verbal and nonverbal communication are continuously emerging, so this paper also remains to be improved. 


\section{REFERENCES}

[1] He Zhaoxiong, Mei Deming. Modern Linguistics [M].Beijing: Foreign Language Teaching and Research Press, 1999.

[2] Chen Yuan. Social Linguistics [M]. Beijing: Academia Press, 1983.

[3] Li Mengya, Zhao Fang. The Nonverbal Communication in Cross-culture Business Communication [J]. The Modern Commercial, 2009(562):199.

[4] Samovar, A. and, Richard E. Porter. Communication Between Cultures [M]. Belmont, CA:, Wadsworth Publishing Co., 2003.

[5] Jin Zhengkun. International Etiquette. Beijing: Peking University Audio and Video Publishing House, 2004.

[6] Kuang Xinhua, Ceng Jianping. On the Communicative Function of Human Language and Its Cultural $[\mathrm{J}]$. Foreign Language and Foreign Language Teaching, 2004 (8): 11-13.

[7] Shi Dingle, Peng Chunping. Business Cross-cultural Communication [M]. Wuhan: Wuhan University Press, 2004.

[8] Dou Weilin, Yang Qining. Business Communication English [M]. Beijing: The Open University of China Press, 2004. 